\title{
Antecipações da metáfora cotidiana nas concepções de Hans Blumenberg e Harald Weinrich
}

\author{
Anticipations of the ordinary language metaphor in the \\ conceptions of Hans Blumenberg and Harald Weinrich
}

\author{
Ulrike Schröder \\ UFMG
}

\begin{abstract}
With the publishing of Metaphors we live by in 1980, Lakoff \& Johnson introduce the Cognitive Metaphor Theory, which rules out the traditional view of metaphor as restricted to its exclusively linguistic use, perceived as an unusual and isolated figure of rhetoric discourse. In contrast, metaphor now is seen as an expression of deeper conceptual structures underlying cognitive capacities in general which help us construct our reality and world view. However, conceptions emphasizing these prescriptive and exploring functions of metaphor already can be found in an explicit way in the metaphorology of Hans Blumenberg as well as in the theory about image fields formulated by the linguist Harald Weinrich. The article deals with the question to what extend these two conceptions already anticipate the Cognitive Metaphor Theory.
\end{abstract}

Keywords

Cognitive Metaphor Theory; Metaphorology; Image field giving/ receiving. 


\section{Resumo}

Com seu livro Metaphors we live by, lançado em 1980, Lakoff \& Johnson introduzem a Teoria Cognitiva das Metáforas, na qual metáforas não são percebidas mais de forma isolada como um fenômeno exclusivo de língua, mas, sim, como uma expressão de estruturas conceptuais e de capacidades cognitivas que servem como base para nossa construção da realidade de forma mais ampla. Não obstante, concepções que destacam essas funções prescritiva, performativa e explorativa da metáfora já se encontram de modo explícito na metaforologia do filósofo Hans Blumenberg bem como na teoria dos campos de imagem do lingüista Harald Weinrich. Será ilustrado até que ponto essas duas concepções já antecipam, em boa parte, a Teoria Cognitiva das Metáforas.

\section{Palavras-chave}

Teoria Cognitiva das Metáforas; Metaforologia; Campo de imagem doador/recebedor. 


\section{Introdução}

$\mathrm{E}$

m geral, quando se fala da teoria cognitiva das metáforas, considera-se a publicação Metaphors we live by, de Lakoff \& Johnson (1980), como o rompimento crucial com a visão aristotélica da metáfora (cf. ARISTOTELES, 1975), predominante, por muito tempo, principalmente no campo dos Estudos Literários e da Retórica. Segundo essa teoria da comparação clássica, as semelhanças postuladas por meio da metáfora podem ser atribuídas às características inerentes dos objetos em si. Em oposição à comparação, a metáfora apenas se distingüe pela falta da partícula comparativa, o que, sobretudo, segundo Quintilian (1986, VIII, 6, 8-9), se abate na definição concisa da metáfora como comparação encurtada. Nessa visão, a função da metáfora limita-se à configuração retórica do discurso. Ela permanece uma figura discursiva da 'fala imprópria', um substituto estético de uma expressão literal, através do qual a metafórica, em geral, mantém um estado de uma anomalia de língua ou de uma divergência da norma. Ora, concomitantemente com o surgimento da Lingüística Cognitiva, a exclusiva reflexão impressionista de metáforas foi retematizada criticamente. Destarte, Lakoff \& Johnson estabelecem um novo conceito da metáfora, no qual metáforas não são percebidas mais de forma isolada como um fenômeno exclusivo de língua, mas, sim, como uma expressão de estruturas conceptuais e de capacidades cognitivas que servem como base para nossa construção da realidade de forma mais ampla.

Não obstante, por trás desse aparente rompimento, observa-se uma certa continuidade de idéias já abordadas, embora a obra de Lakoff \& Johnson, indubitavelmente, introduza uma mudança paradigmática de modo mais explícito, ainda que apenas com base nos inúmeros exemplos dados da fala cotidiana. De fato, tematizações que se opõem à compreensão clássica da metáfora por ilustrar sua força criadora de experiência já são observadas em reflexões filosóficas há muito tempo. A elas pertencem os pensamentos de John Locke, Giambattista Vico, Immanuel Kant, Johann Gottfried Herder, Friedrich Nietzsche, Fritz 
Mauthner, Ernst Cassirer ou Arnold Gehlen (cf. SCHRÖDER, 2004; JÄKEL, 2003; BALDAUF, 1997). São reflexões que necessariamente tiveram que surgir junto com o questionamento epistemológico da idéia objetivista, que entende a língua como espelho ou mapeamento da realidade. Todavia, a maioria dessas abordagens trata da metáfora apenas de forma fragmentária, com respeito a um desdobramento sistemático da função fundamental que conceitos metafóricos cumprem em nossa exploração da realidade.

Em virtude do desenvolvimento da Lingüística Antropológica norteamericana, são retomadas as idéias dos proponentes alemães Kant, Herder e Humboldt, para provar a hipótese do princípio da relatividade lingüística em estudos empíricos. Nisso, já Edward Sapir (1949, p. 10) menciona o aspecto criativo e, ao mesmo tempo, recursivo do falar metafórico na construção de uma visão do mundo culturalmente fixado. Finalmente, Benjamin Lee Whorf (1973) aprofunda esse aspecto, analisando as metáforas e sua relatividade cultural no contexto do seu conhecido e polêmico estudo sobre os índios Hopi, no qual ele revela alguns conceitos metafóricos que se encontram na maioria das línguas do SAE (Standard Average European), mas que, segundo ele, de modo algum são universalmente válidos.

No campo da Lingüística, na Europa, entender o metafórico como um princípio onipresente em qualquer tipo textual é preparado pela obra Cours de linguistique générale, de Saussure (1916), cuja inovação essencial consiste na transformação do significado de uma cópia pré-lingüística e natural do objeto em uma parte do signo em si. A arbitrariedade e convencionalidade que a tradição ocidental desde Aristóteles concede aos significantes como imagens acústicas das línguas diferentes estende-se, aqui, também aos significados: a idéia que se faz de algo não aparece mais como entidade natural, cópia da coisa em si, mas, sim, é determinada pelo que foi nomeado em uma metáfora pós-estruturalista como jogo dos significantes. ${ }^{1}$

Como veremos adiante, nos anos sessenta do século passado, surgem os trabalhos de dois alemães, o filósofo Hans Blumenberg e o lingüista Harald Weinrich, que antecipam a teoria cognitiva das metáforas em muitos aspectos por uma dedicação exclusiva à metáfora como um fenômeno-chave para a experiência humana e não restrita ao reino da língua. 


\section{A exploração da realidade cotidiana por meio de conceitos metafóricos na teoria cognitiva de Lakoff \& Johnson}

Seguindo a versão holística da Lingüística Cognitiva, Lakoff \& Johnson observam a metáfora como um fenômeno cotidiano onipresente no qual seus lados lingüístico e cognitivo são entrelaçados de modo inextricável. Desta forma, em expressões como frases vazias, palavras abertas ou papo furado, a FALA é fixada pela imagem de um CONTAINER; em expressões como batalha das eleições, guerra de partidos ou embate da oposição, POLÍTICA é fixada pela imagem da GUERRA. Entretanto, não se trata meramente de um fenômeno lingüístico, mas, sim, do modo de processamento da cognição humana que, por meio de metaforizações diferentes, sistematiza experiências, atribuindo sentido a elas. Essa ancoragem da descrição metafórica do mundo na experiência é denominada pelos autores como experientalism (LAKOFF; JOHNSON, 1980, p. 226). Nesta perspectiva, o processo da formação da metáfora é descrito como um processo de seleção e predicação, isto é, há um acoplamento de dois domínios de língua significativos por projetar uma parte das características do domínio original ao domínio destinatário, ainda não estruturado. Para Lakoff \& Johnson, a conexão entre esses dois domínios torna-se eixo da sua compreensão de metáfora. Isto leva os autores à conclusão de que a maior parte da nossa experiência cotidiana apenas se torna coerente por estabelecer correspondências entre uma área de experiência já deduzida conceptualmente e uma outra ainda não estruturada. Destarte, há uma interligação entre dois domínios conceptuais, o domíniofonte e o domínio alvo, que serve à transferência metafórica como expressão de um processo cognitivo submetido (cf. LAKOFF; JOHNSON, 1980, p.5).

Recorrendo à Psicologia da Gestalt, que serviu como base para a formação da variante holística da Lingüística Cognitiva, Lakoff transfere a noção de gestalt à lingüística, salientando que

thought, perception, the emotions, cognitive processing, motor activity, and language are all organized in terms of the same kind of structures, which I am calling gestalts. Gestalts are at once holistic and analyzable. They have parts, but the wholes are not reducible to the parts (LAKOFF, 1977, p. 246).

A partir de um tal realismo encarnado, ele desenvolve sua teoria dos ICM, Idealized Cognitive Models (LAKOFF, 1987), que se referem a modelos da 
realidade como estruturas, representando de modo idealizado experiências recorrentes e válidas intersubjetivamente. Por conseguinte, tais modelos formam o pano de fundo do nosso conhecimento e entendimento de conceitos singulares. Assim, um conceito como terça-feira apenas obtém seu significado como construto humano carregado por todas suas conotações culturais perante o ICM semana. Dessa forma, conceitos são partes de ICMs e podem ressaltar e configurar um conceito concreto perante um pano de fundo como um todo. ${ }^{2}$ Por sua vez, ICMs representam coesões estruturais que juntam conceitos metafóricos, formando, desse modo, teorias cotidianas, isto é, padrões específicos de cultura para a explicação do mundo que residem implicitamente nas estruturas metafóricas, determinando o pensamento e os atos dos falantes. Com isso, a teoria cognitiva das metáforas, em boa parte, explica o funcionamento de estruturas cognitivas e sua contribuição à nossa organização do conhecimento.

\section{A metáfora na concepção de Hans Blumenberg}

Durante os anos sessenta, o filósofo Hans Blumenberg começa a dedicar-se ao desenvolvimento da sua metaforologia em dois ensaios fundamentais: Paradigmen zu einer Metaphorologie, ${ }^{3}$ publicado em 1960, e Beobachtungen anMetaphern, ${ }^{4}$ de $1971 .{ }^{5}$ Focalizando os paradigmas que conduzem e conduziam as grandes reflexões filosóficas, ele reconstrói os modelos metafóricos submetidos às idéias de uma certa corrente. Destarte, o acesso de Blumenberg ao fenômeno da metáfora também parte de uma perspectiva construtivista, substituindo, com isso, a idéia de que metáforas estabelecem analogias com um mundo externo:

Was bleibt dem Menschen? Nicht die $>$ Klarheit $<$ des Gegebenen, sondern die des von ihm selbst Erzeugten: die Welt seiner Bilder und Gebilde, seiner Konjekturen und Projektionen, seiner $>$ Phantasie< in dem neuen produktiven Sinne, den die Antike nicht gekannt hatte $^{6}$ (BLUMENBERG, 1960/1998, p. 8).

A partir de exemplos da História Intelectual e da Filosofia, a publicação Paradigmen zu einer Metaphorologie pretende revelar o fato de que certas metáforas, como a da VERDADE NUA, devem ser vistas como pertencentes ao estoque da língua filosófica e não podem ser substituídas por termos técnicos 
que exprimam um 'logicismo puro'. Tais metáforas absolutas, como Blumenberg as denomina, constituem um esboço da realidade à qual a ação e o pensamento humanos se orientam. Em seguida, Blumenberg reconstrói o uso da metafórica da LUZ e da LEGIBILIDADE do mundo em contextos epistemológicos e faz o mesmo com o uso da metafórica do NAUFRÁGIO em contextos existenciais, entre outros. Ora, a metáfora é caracterizada como um modelo na sua função pragmática, do qual é extraída uma regra de reflexão. Nesse sentido, já Blumenberg destaca o valor explorativo de metáforas:

Ihr Gehalt bestimmt als Anhalt von Orientierungen ein Verhalten, sie geben einer Welt Struktur, repräsentieren das nie erfahrbare, nie übersehbare Ganze der Realität. Dem historisch verstehenden Blick indizieren sie also die fundamentalen, tragenden Gewißheiten, Vermutungen, Wertungen, aus denen sich die Haltungen, Erwartungen, Tätigkeiten und Untätigkeiten, Sehnsüchte und Ettäsuchungen, Interessen und Gleichgültigkeiten einer Epoche regulierten ${ }^{7}$ (BLUMENBERG, 1960/1998, p. 25).

Na concepção da metáfora de Blumenberg, já é possível observar alguns aspectos que correspondem à delineação de Lakoff \& Johnson sistematizada pelo lingüista Olaf Jäkel (2003, p. 40-41) em nove teses básicas que vislumbram a teoria cognitiva das metáforas. Percebe-se que a maioria das teses já se encontra no pensamento de Blumenberg, entre elas (1) a tese do domínio: metáforas não podem ser vistas isoladas, mas conceptualmente; (2) a tese do modelo: metáforas conceptuais formam modelos cognitivos com estruturas da organização do conhecimento; (3) a tese da diacronia: estudos sobre o desenvolvimento histórico de metáforas conceptuais revelam mudanças de pensamento; e (4) a tese da criatividade: a metáfora é aberta para inúmeros novos caminhos de pensamento. Mais um fator fundamental é ressaltado e descrito por Blumenberg, a saber, a interligação indissolúvel entre os lados cognitivo e lingüístico da metáfora. Blumenberg aplica o termo modelo implicativo (1960/1998, p. 14-22) para se referir ao fato de que, muitas vezes, metáforas não necessariamente se exprimem de forma lingüística, mas, sim, submetem-se ao contexto a partir do qual pode ser explorada uma imaginação condutora. Dessa forma, muitas idéias filosóficas ou seguem uma imaginação condutora mais orgânica, ou uma mais mecânica. Para esse fenômeno, Blumenberg introduz o termo Hintergrundmetaphorik ${ }^{8}$ 
(BLUMENBERG, 1960/1998, p. 91-110). Segundo ele, as explicações dadas encaixam-se em um pano de fundo que fornece uma imagem subjacente como orientação básica. Assim, a interpretação aristotélica da técnica em termos da mimese, por exemplo, indica uma perspectiva orgânica, ao passo que, junto com o surgimento da metáfora do relógio, como se estabelece durante o século dezoito nas reflexões de La Mettrie ou Voltaire, é introduzido o modelo de um mundo 'funcionando' de forma automática sem ingredientes transcendentais. Para Descartes, há um mecanismo universal, sendo a natureza a unidade de agregados mecânicos, o que inverte o pensamento aristotélico.

Neste ponto, observa-se um forte paralelo com a Psicologia da Gestalt e com a organização de perfil/base conforme Langacker, ou seja, com o conceito dos modelos cognitivos idealizados por Lakoff que ilustram esse entrelaçamento de língua e cognição. Daí, Blumenberg desdobra seu projeto de uma metaforologia cujo objetivo é a reconstrução das metáforas que constituem nosso modelo do mundo e seu processamento cognitivo-lingüístico:

die Metaphorologie sucht an die Substruktur des Denkens heranzukommen, an den Untergrund, die Nährlösung der systematischen Kristallisationen. [...] Denn hier finden wir Orientierungen, die abgelesen werden an ganz elementaren Modellvorstellungen, die in der Gestalt von Metaphern bis in die Ausdruckssphäre durchschlagen ${ }^{9}$ (BLUMENBERG, 1960/1998, p. 13).

Blumenberg dedica-se a análises de vários conceitos metafóricos: o esboço da VERDADE como LUZ ou ATOR e do MUNDO como VIVO, RELÓGIO, BARCO, TEATRO ou LIVRO (cf. BLUMENBERG, 1960/1998), a descrição da HISTÓRIA REAL como CONTO, da VIDA como PASSEIO DE BARCO e de DOCUMENTOS como FONTES (cf. BLUMENBERG, 1971), e, finalmente, a estruturação do TEMPO como ESPAÇO, referindo-se, mais uma vez, à base fisiológica dessa metáfora por indicar que, em nosso cérebro, as orientações espaciais são mais velhas do que as temporais (cf. BLUMENBERG, 1971, p. 166). As expressões metafóricas, portanto, têm sua base em experiências básicas. Desse modo, Blumenberg quer descobrir por que a metafórica da existência náutica, que também é analisada dentro do conceito LIFE IS A JOURNEY por Lakoff \& Turner (1989, p. 81), vem sendo, por séculos, tão 
onipresente em reflexões filosóficas. Ele chega à conclusão de que, entre as realidades elementares que o homem tem que enfrentar, aquela do mar é a que mais gera desconfiança. São os deuses e os monstros marítimos que dominam essa esfera. Destarte, desenvolve-se uma contraposição entre a terra firme e o mar irrequieto como semântica-chave para o paradoxo da existência humana, uma metáfora que Blumenberg vê atuando até em debates políticos atuais sobre o orçamento do estado (cf. BLUMENBERG, 1997, p. 14). Isso mostra que é correto afirmar que sua abordagem compreende por maior parte uma análise da linguagem filosófica. Não obstante, não se limita a isso. Ora, quando o indivíduo começa a se liberar das forças superiores, essa imagem de naufrágio torna-se cada vez mais positivamente conotada: a situação inicial, agora, é o náufrago; a construção de um barco surge posteriormente como ato de auto-afirmação.

\section{A metáfora na concepção de Harald Weinrich}

Harald Weinrich alinha-se na tradição alemã da Sprachinhaltsforschung, ${ }^{10}$ fundada por Leo Weisgerber. Ela tem suas raízes na visão da língua energética de Wilhelm von Humboldt e concebe a língua como uma força ativa (energeia) cuja forma interna reflete uma visão do mundo específica. Um teórico ligado a essa linha é o semanticista de campo Jost Trier (1934), a quem Weinrich se reporta explicitamente em suas exposições. As reflexões de Weinrich sobre metáforas encontram-se em cinco ensaios: Münze und Wort: Untersuchungen an einem Bildfeld ${ }^{11}$ (1958), Semantik der kühnen Metapher ${ }^{12}$ (1963), Metaphora memoriae (1964), Allgemeine Semantik der Metapher ${ }^{13}$ (1967) e Streit um Metaphern $^{14}$ (1976), todos reunidos no livro Sprache in Texten ${ }^{15}$ (1976). Em comparação com Blumenberg, a concepção de Weinrich aproxima-se ainda mais dos pensamentos de Lakoff \& Johnson pelo estabelecimento de uma Bildfeldtheorie, ${ }^{16}$ que parte da pressuposição de que exista um mundo coletivo de imagens como estoque objetivo de qualquer comunidade cultural. Weinrich também não observa a metáfora em isolamento, mas, sim, em coesão, o que se abate no seu termo central campo: o homem vive sempre em tradições metafóricas que podem ser analisadas ou de modo diacrônico, ou de modo sincrônico. Ora, Weinrich ressalta que a metafórica diacrônica é unilateral por isolar a metáfora singular do sistema inteiro. Entretanto, a metáfora não apenas se encontra de modo diacrônico numa linha de tradição, mas também de modo sincrônico em um contexto interno com 
outras metáforas que podem ser apresentadas sistematicamente. Em conformidade com isso, Weinrich revela a conexão de campos metafóricos como objetivo principal de uma metafórica sincrônica. Para tal tarefa, o termo campo de imagem é desenvolvido por ele em analogia ao termo campo lexical ou campo semântico da área lingüística. Na medida em que a palavra singular não tem existência isolada em um sistema de língua, também a metáfora singular já pertence à conexão do respectivo campo de imagem. Neste ponto, mostrase a influência de Saussure, segundo o qual o significante pode modificar seu significado em dependência dos significados atuais dos outros significantes aos quais está interligado, isto é, o significante é distintivo. Partindo da semântica de campo, Weinrich passa para a metafórica: a metáfora atualmente dada é compreendida sem qualquer problema porque é integrada a um campo de imagem dado, implicando metáforas paralelas estabelecidas pela tradição da respectiva comunidade cultural. Na metáfora atual, na verdade, executa-se o acoplamento de dois domínios de sentido: ao se falar da riqueza ou do tesouro de uma língua, ou mesmo quando nos referimos a Goethe como um clássico, aplicamos o mesmo campo de imagem:

Insofern zwei Sinnbezirke Bestandteile eines Bildfeldes sind, benennen wir sie (mit Ausdrücken von Jost Trier) als bildspendendes und bildempfangendes Feld. In unseren Beispielen wird das bildempfangende Feld vom Sinnbezirk Sprache gebildet, das bildspendende Feld vom Sinnbezirk des Finanzwesens; das Bildfeld, das sich in der Koppelung der beiden Sinnbezirke konstituiert, wollen wir nach seiner Zentralmetapher, Wortmünze ' benennen ${ }^{17}$ (WEINRICH, 1976, p. 284).

Em seguida, Weinrich reconstrói vários campos de imagem concretos, por exemplo, o BARCO DO ESTADO, a GUERRA DO AMOR, o TEATRO DO MUNDO, o SUCO DA VIDA, a CAÇADA VIDA, o REINO DOS ANIMAIS, a LUZ DARAZÃO, o BARCO DO AR, o CRIADOR DO POETA, a CULPA DO PECADO, o TECIDO DO TEXTO, o JOGODAEXISTENCIA, a PLANTA DA LÍNGUA, a PAISAGEM DO AMOR, a VIAGEM DA VIDA, o REINO DO CÉU, a TERRA DO ESPÍRITO (WEINRICH, 1976, p. 285). Observando o campo de imagem recebedor MEMÓRIA, Weinrich constata que há certas preferências quanto à escolha do campo de imagem doador, a saber, ou a 
metáfora do ESTOQUE ou aquela da tábua de cera. A consistência de tais campos de imagem levam Weinrich a concluir que elas têm um valor constitutivo como modelo de pensamento (WEINRICH, 1976, p. 291). Por conseguinte, para tematizar um certo assunto, por exemplo, a língua em geral, dispomos de uma escolha definida de campos de imagens, nesse caso, daqueles da MOEDA, da PLANTA, da CONSTRUÇÃO DO TEXTO, ou do TECIDO, entre outros. Recorrendo a Humboldt e Weisgerber, Weinrich concebe os campos de imagem como carimbo para uma certa visão do mundo de uma comunidade, que não se limita necessariamente à uma língua específica. Para ele, o Ocidente seria uma tal comunidade de campo de imagem (WEINRICH, 1976, p. 287).

Retornando às teses de Jäkel, pode-se observar que Weinrich também segue pressuposições semelhantes àquelas de Lakoff \& Johnson. Ainda mais do que Blumenberg, Weinrich salienta que metáforas não podem ser analisadas isoladamente; elas têm que ser compreendidas como pertencentes a um campo de sentido inteiro. Ele afirma também que os campos de imagens servem como base para modelos de pensamento que têm como objetivo a exploração da realidade, o que implica uma perspectiva construtivista:

[...] dann drängt sich uns die Gewißheit auf, daß unsere Metaphern gar nicht, wie die alte Metaphorik wahrhaben wollte, reale oder vorgedachte Gemeinsamkeiten abbilden, sondern daß sie ihre Analogien erst stiften, ihre Korrespondenzen erst schaffen und somit demiurgische Werkzeuge sind ${ }^{18}$ (WEINRICH, 1976, p. 309).

Finalmente, um item importante vem a ser a integração de aspectos semântico-textuais nas reflexões de Weinrich, o que constitui um ganho fértil em comparação com a teoria de Lakoff \& Johnson. Weinrich não dirige sua atenção apenas às estruturas conceptuais que subjazem às formas lingüísticas, como críticos observam no caso da teoria de Lakoff \& Johnson (segundo estes, a metáfora conceptual organizaria o nosso modo de representação e categorização do mundo, ao passo que a metáfora lingüística daria forma lingüística ao processo cognitivo subjacente). De fato, questiona-se se a metáfora conceptual é logicamente anterior à metáfora lingüística (LEEZENBERG, 2001, p. 145). Em sua recente pesquisa, Melo Moura demonstra que a metáfora "depende não apenas da metáfora conceptual subjacente, mas também de regularidades linguiísticas que restringem diferentes tipos de interpretação. Assim, a expressão 
lingüística não é considerada como logicamente posterior à estrutura conceptual: língua e estrutura conceptual interagem de uma forma bidirecional" (MELO MOURA, 2005, p.116). Como Jäkel (2003, p. 127) destaca, é exatamente esse aspecto que já se vê considerado na teoria de Weinrich pela introdução do termo Kondetermination ${ }^{19}$ (WEINRICH, 1976, p. 320): já no nível meramente semântico, observa-se que o contexto textual de uma palavra reduz as possibilidades do significado. Agora, Weinrich enfatiza que este aspecto ainda se torna mais crucial no caso da metáfora, que não pode ser desligada de forma alguma das suas condições textuais:

Ein beliebiges Wort kann isoliert gebraucht werden, z.B. in einer wortgeschichtlichen Untersuchung, also metasprachlich. Wer jedoch eine Metapher von jeglichem Kontext [...] zu entblößen versucht, zerstört damit die Metapher. Eine Metapher ist folglich nie ein einfaches Wort, immer ein - wenn auch kleines - Stück Text ${ }^{20}$ (WEINRICH, 1976, p. 319).

De acordo com isso, para Weinrich, a semântica da palavra tem que ser transformada em uma semântica do texto, pois apenas a junção da palavra e do contexto criam a metáfora. Quanto mais original uma metáfora é, tanto maior é o efeito de surpresa e de tensão entre o significado original e o novo significado nascido no contexto textual, ou seja, o significado gerado pelo contexto, muitas vezes, está fora do campo semântico original. Por isso, Weinrich chama esse processo con-determinação, porque a determinação do contexto dirige-se contra a expectativa da determinação da palavra.

\section{Conclusões}

Contra a opinião ainda bastante difundida em muitos estudos sobre metáforas de que a teoria de Lakoff \& Johnson introduz um rompimento radical com a idéia clássica da metáfora, foi ilustrado que já se encontram fragmentos de uma compreensão mais ampla do fenômeno metafórico nos campos filosófico, lingüístico e antropológico. Além disso, a teoria tem dois precursores quase imediatos que já preparam e desenvolvem uma boa parte da concepção da metáfora cotidiana. Enquanto Blumenberg estabelece o termo metafórica do pano de fundo que antecipa a metáfora estrutural de Lakoff \& Johnson, 
Weinrich desenvolve uma teoria sobre campos de imagem em analogia aos campos semânticos ou lexicais da lingüística. Ainda, os dois já interligam a esfera da língua com aquela da cognição, de modo que Weinrich chega a falar de modelos de pensamento, semelhantemente aos modelos cognitivos idealizados, termo proposto por Lakoff. Em comparação com Blumenberg, Weinrich concentrase mais em uma análise sincrônica por garantir a observação do campo inteiro integrando também observações semânticas de texto. Finalmente, ele desenvolve os termos campo de imagem doador e recebedor, que correspondem aos termos domínio fonte e alvo de Lakoff \& Johnson. Embora as colunas teóricas de Lakoff \& Johnson, diante dessa demonstração de uma certa continuidade no tratamento da metáfora como um fenômeno cognitivo e onipresente, percam parte da sua originalidade, não se deve esquecer de que a grande contribuição deles, por fim, reside na ilustração singular de como nossa vida cotidiana é impregnada por conceitos metafóricos a cada momento.

\section{Notas}

${ }^{1}$ Dessa forma, Derrida conclui "A ausência de significado transcendental amplia indefinidamente o campo e o jogo da significação" (2002, p. 232).

${ }^{2}$ Cf. também a gramática cognitiva de Langacker (1988, p. 59), na qual ele aprofunda sua hipótese de que o conhecimento relevante para a constituição de significados seja representado por domínios cognitivos. Por conseguinte, o significado da palavra hipotenusa somente pode ser entendido por meio do enquadramento no conceito triângulo retangular. Tais quadros de referência são gestalts holísticas dos quais o significante aparece como perfil, enquanto o resto da gestalt forma a base que fornece o conhecimento do pano de fundo (LANGACKER, 1987, p. 183).

${ }^{3}$ Paradigmas a uma Metaforologia.

${ }^{4}$ Observações em Metáforas.

${ }^{5}$ Uma visão geral dos aspectos epistemológicos, antropológicos e históricos da metaforologia de Hans Blumenberg é fornecida por Jörg Haefliger (1996).

${ }^{6} \mathrm{O}$ que resta ao homem? Não a >clareza< do dado, mas sim, a do próprio construto: o mundo das suas imagens e composições, das suas conjecturas e projeções, da sua $>$ fantasia $<$ no novo sentido produtivo que a Antigüidade não tinha conhecido.

${ }^{7}$ Como orientações, seu conteúdo determina um comportamento, elas dão estrutura ao mundo, representando o todo da realidade que nunca pode ser experimentado e visto inteiramente. Então, ao olhar compreensivo histórico, elas indicam as certezas, 
suposições e valorizações fundamentais e sustentáveis a partir das quais se regulavam as atitudes, expectativas, atividades e inatividades, saudades e decepções, interesses e indiferenças de uma época.

${ }^{8}$ Metafórica do pano de fundo

${ }^{9}$ A metaforologia procura aproximar-se da subestrutura do pensamento, do subterrâneo, o frutífero das cristalizações sistemáticas. [...] Pois, aqui, encontramos orientações que são decifradas em idéias modeladas de forma inteiramente elementar que passam, sob a forma de metáforas, até a esfera de expressão.

${ }^{10}$ Investigação do conteúdo da linguagem.

${ }^{11}$ Moeda e palavra: Pesquisas sobre um campo de imagem.

${ }^{12}$ Semântica da metáfora ousada.

${ }^{13}$ Semântica geral da metáfora.

${ }^{14}$ Briga por metáforas.

${ }^{15}$ Lingua em textos.

${ }^{16}$ Teoria do campo de imagem.

${ }^{17}$ Assim que dois domínios de sentido representarem partes de um campo de imagem, (com os termos de Jost Trier) os denominamos como campo de imagem doador e campo de imagem recebedor. Em nossos exemplos, o campo de imagem recebedor é formado pelo domínio de sentido língua, o campo de imagem doador pelo domínio de sentido da economia; queremos denominar o campo de imagem que se constitui no acoplamento dos dois domínios de sentido 'moeda de palavra', segundo sua metáfora central.

${ }^{18}$ [...] aí, impõe-se a certeza de que nossas metáforas não espelham similaridades reais ou pré-pensadas, mas, sim, que, de todo, elas criam suas analogias, elas criam suas correspondências, sendo, assim, instrumentos demiúrgicos.

${ }^{19}$ Con-determinação.

${ }^{20}$ Qualquer palavra pode ser usada de forma isolada, por exemplo, numa pesquisa histórico-lexical, então, de modo metalingüístico. Quem tenta, porém, desnudar uma metáfora de todo seu contexto, destrói, com isso, a metáfora. Portanto, uma metáfora nunca é apenas uma palavra simples, é sempre um pedaço de um texto, mesmo pequeno. 


\section{Referências Bibliográficas}

ARISTOTELES. The 'Art' of Rhetoric. London: Duckworth, 1975.

BALDAUF, C. Metapher und Kognition. Grundlagen einer neuen Theorie der Alltagsmetapher. Frankfurt am Main: Peter Lang, 1997.

BLUMENBERG, H. Paradigmen zu einer Metaphorologie. Frankfurt: Suhrkamp, 1960/1998.

BLUMENBERG, H. Schiffbruch mit Zuschauer. Paradigma einer Daseinsmetapher. Frankfurt: Suhrkamp, 1997.

BLUMENBERG, H. Beobachtungen an Metaphern. In: GRÜNDER, K. (Ed.) Archiv für Begriffsgeschichte. Bd. 15. Bonn: Bouvier, 1971. p. 161-214.

DERRIDA, J. A escritura e a differença. São Paulo: Perspectiva, 2002.

HAEFLIGER, J. Imaginationssysteme. Erkenntnistheoretische, anthropologische und mentalitätshistorische Aspekte der Metaphorologie Hans Blumenbergs. Bern: Lang, 1996.

JÄKEL, O. Wie Metaphern Wissen schaffen: die kognitive Metapherntheorie und ihre Anwendung in Modell-Analysen der Diskursbereiche Geistestätigkeit, Wirtschaft, Wissenschaft und Religion. Hamburg: Kovaè, 2003.

LAKOFF, G. Women, Fire, and Dangerous Things: What Categories Reveal about the Mind. Chicago, London: The University of Chicago Press, 1987.

LAKOFF, G. Linguistic Gestalts. Chicago Liguistic Society, v. 13, p. 236-287, 1977.

LAKOFF, G.; JOHNSON, M. Metaphors We Live By. Chicago: The University of Chicago Press, 1980.

LAKOFF, G.; TURNER, M. More than Cool Reason: A Field Guide to Poetic Metaphor. Chicago, London: The University of Chicago Press, 1989.

LANGACKER, R. W. A View of Linguistic Semantics. In: RUDZKA-OSTYN, B. (Ed.). Topics in Cognitive Linguistics. Amsterdam: Benjamins, 1988. p. 49-90.

LANGACKER, R. W. Foundations of Cognitive Grammar. Volume I: Theoretical Prerequisites. Stanford, California: Stanford University Press, 1987.

LEEZENBERG, M. Contexts of Metaphor. Amsterdam: Elsevier, 2001.

MELO MOURA, H. M. Metáforas e regularidades lingüísticas. In: MIRANDA, N. S.; NAME, M. C. (Ed.). Lingüística e cognição. Juiz de Fora: Editora UFJF, 2005. p. 109-119. 
QUINTILIAN, M. F. Werkausgabe. Band 3. Cambridge, Mass., London: Harvard University Press, 1986.

SAPIR, E. Selected Writings of Edward Sapir in Language, Culture and Personality. Berkely, Los Angeles: University of California Press, 1949.

SAUSSURE, F. Cours de linguistique générale. Paris: Payot, 1916.

SCHRÖDER, U. Os precursores filosóficos da teoria cognitiva das metáforas. Cadernos de Estudos Lingüísticos, v. 46, n. 2, p. 243-252, 2004.

TRIER, J. Deutsche Bedeutungsforschung. In: GÖTZE, A.; HORN, W.; MAUER, F. (Ed.). Germanische Philologie: Ergebnisse und Aufgaben. Festschrift für Otto Behaghel. Heidelberg: Carl Winters Universitätsbuchhandlung, 1934. p. 173-200. WEINRICH, H. Sprache in Texten. Stuttgart: Ernst Klett, 1976.

WHORF, B. L. Language, Thought and Reality. Selected Writings of Benjamin Lee Whorf. Cambridge, Massachusetts: The M.I.T. Press, 1973. 